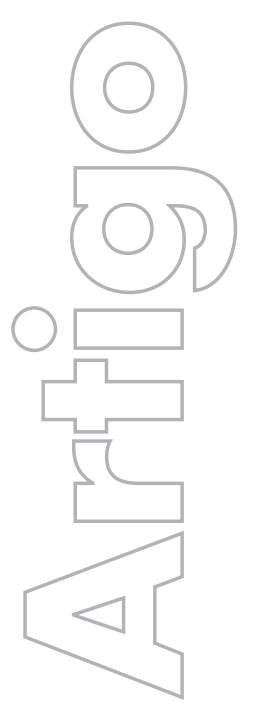

revista

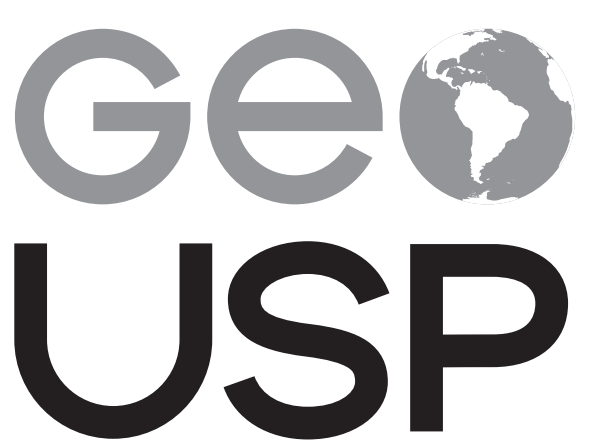

espaço e tempo

Volume $23 \cdot n^{\circ} 1$ (2019)

ISSN 2179-0892
Território, cultura

e identidade dos

colonizadores italianos no

Rio Grande do Sul: uma

análise da Serra Gaúcha e

da Quarta Colônia

\author{
Vanessa Manfio \\ UFRGS \\ e-mail: vamanfio@hotmail.com \\ Vinício Luís Pierozan \\ UFRGS \\ e-mail: vpierozan@hotmail.com
}

p. $144-162$

Como citar este artigo:

MANFIO, V.; PIEROZAN, V. L. Território, cultura e identidade dos colonizadores italianos no Rio Grande do Sul: uma análise da Serra Gaúcha e da Quarta Colônia. Geousp - Espaço e Tempo (Online), v. 23, n. 1, p. 144-162, abr. 2019. ISSN 2179-0892.

Disponível em: https://www.revistas.usp.br/geousp/article/ view/146130. doi: https://doi.org/10.11606/issn.2179-0892. geousp.2019.146130.

\section{(c) $(1) \circledast$}

Este artigo está licenciado sob a Creative Commons Attribution 4.0 License. 


\title{
Território, cultura e identidade dos colonizadores italianos no Rio Grande do Sul: uma análise da Serra Gaúcha e da Quarta Colônia
}

\section{Resumo}

A colonização do Rio Grande do Sul tem particularidades significativas, especialmente a italiana, que é responsável pela constituição de territórios. Este trabalho discute os territórios articulados pela presença italiana no Rio Grande do Sul, hoje com territorialidades preservadas por seus descendentes, tendo como área de estudo a Serra Gaúcha e a Quarta Colônia. Nesse sentido, se entrecruzam as diferentes singularidades dos dois territórios, como, por exemplo, a cultura italiana, sua identidade e seu modo de vida, atributos fundamentais para o entendimento da formação dos territórios. Para atingir os objetivos propostos, adotaram-se o trabalho de campo, a revisão de literatura, a abordagem empírica, a coleta de dados e materiais e técnicas conduzidas por abordagem qualitativa.

Palavras-chave: Território. Identidade italiana. Cultura. Serra Gaúcha. Quarta Colônia.

\section{Territory, culture and identity of the Italian settlers in Rio Grande do Sul: an analysis on the Serra Gaúcha and the Fourth Colony}

\begin{abstract}
The colonization of Rio Grande do Sul presents significant particularitities, especially the Italian, which is responsible for the constitution of territories. Therefore, this work aims to discuss about the articulated territories by the Italian presence in the Rio Grande do Sul, and that currently presents territorialities preserved by their downward, having as study area the Serra Gaúcha and the Fourth Colony, seeking to establish a cross between the different singularities particular to the two territories, such as Italian culture, identity and way of life, fundamental attributes for the understanding of the formation of territories.
\end{abstract}


To reach the proposed objectives the methodology was based on field work, literature review, empirical approach, data collection and materials, conducted this techniques by the qualitative approach.

Keywords: Territory. Italian identity. Culture. Serra Gaúcha. Fourth Colony.

\section{Introdução}

território é um espaço de apropriação de um grupo social que mantém diferentes relações estabelecidas entre si e com outros indivíduos. Estas afinidades são entendidas como territorialidades podem ser de ordem econômica, política, social e cultural. Ainda, a formação territorial está ligada a identidade que se articula neste território e o sentimento de pertencimento a ele associado.

Assim, território é um conceito geográfico muito complexo, mas que tem interessado pesquisadores das mais variadas áreas do conhecimento. $\mathrm{Na}$ Geografia, nos últimos anos, tem ocorrido uma proliferação de estudos envolvendo esta temática de análise, partindo de diferentes realidades, escalas e dinâmicas.

Nota-se que a colonização realizada no Brasil permitiu a formação de territórios com marcas identitárias de grupos étnicos. Os italianos formaram vários territórios marcados pela sua presença e de seus descendentes. Isto devido, principalmente ao processo de desterritorialização dos italianos da Itália por problemas socioeconômicos e pela sua reterritorialização em solo brasileiro.

Nesse sentido, este trabalho discute os territórios italianos formados pelo processo de colonização italiana, realizado na Serra Gaúcha e na Quarta Colônia, ambos no estado do Rio Grande do Sul, estabelecendo um cruzamento de aspectos (cultura italiana, identidade, modo de vida) importantes para o entendimento da constituição dos territórios. Neste artigo, esses territórios são chamados de Territórios da Cultura Italiana.

Para cumprir com esses objetivos, adotaram-se como procedimentos metodológicos: trabalho de campo, revisão de literatura, coleta de dados e materiais, revisão de literatura, conduzidas pela abordagem qualitativa. Na literatura, destacam-se Briskievicz (2012), Buchmann (1995), Haesbaert (2004, 2005), Medeiros (2009), Saquet (2003, 2015), entre outras.

Finalmente, este artigo está organizado em três partes: uma discussão teórica dos conceitos de território e identidade, uma análise dos territórios da Serra Gaúcha e da Quarta Colônia e as considerações finais.

\section{Território e identidade cultural: discussões relevantes}

Território é um conceito importante da geografia e vem sendo frequentemente abordado nas análises científicas, principalmente por revelar a relação da sociedade com a natureza. Nesse sentido, vários autores têm contribuído para a discussão dessa temática, entre eles destacam-se: Claude Raffestin, Rogério Haesbaert, Milton Santos, Marcos Aurélio Saquet, Marcelo Lopes de Souza. 
conceito de território está associado às relações de poder, à apropriação espacial, à identidade de um grupo social e à sua reprodução cotidiana. Segundo Saquet e Briskievicz (2009), o território compreende quatro componentes importantes: (a) as relações de poder, (b) as redes de circulação e comunicação, (c) as identidades e (d) a natureza.

Para Haesbaert (2004, p. 79), "o território pode ser concebido a partir da imbricação de múltiplas relações de poder, do poder mais material das relações econômicas e políticas ao poder mais simbólico das relações de ordem mais estritamente cultural." Reforça Saquet (2015) que o território é o resultado de um processo de produção/apropriação do/no espaço. Sendo constituído socialmente a partir de territorialidades (relações cotidianas).

território pode ser material e imaterial, pois é tecido pela apropriação espacial do espaço geográfico no qual o homem passa a estabelecer distintas relações de poder, mas também envolve questões como sentimento, emoção, linguagem que são aspectos da imaterialidade.

Além disso, o território pode ser sonhado, ideológico ou imaginado, já que, às vezes, este permanece apenas na lembrança e pensamento do grupo social ou indivíduo, podendo efetivar ou não a materialidade territorial. Para Medeiros (2009, p. 217), "O território pode mesmo ser imaginário e até mesmo sonhado. E, é a partir deste imaginário, deste sonho que sua construção tem início".

Isto é evidenciado na reterritorialização dos colonos italianos no Brasil, já que os italianos ao chegar ao Brasil passaram a reproduzir sua cultura, e exaltar as memórias da Itália, com um verdadeiro sonho de produzir uma nova vida. Aos poucos, estes italianos foram articulando a formação de territórios marcados pela sua presença e relações de vida cotidiana. Para Brum Neto (2012, p. 58), os grupos sociais que migram de nação "abandonam seus territórios, procurando reconstruí-lo em outros lugares".

De acordo com Frosi e Mioranza (2009, p. 102-103), os italianos: "Traziam da pátria a convicção intima e singela, quase um sonho, de construir grandes cidades, grandes centros econômicos, conforme atestam cartas enviadas desta região à imprensa do Norte da Itália, nos fins do século XIX e início do século XX.".

Assim, a desterritorialização destes italianos implicou numa reterritorialização no Brasil, sendo, portanto, fenômenos que fazem parte do mesmo processo. Conforme Saquet (2003), os processos de territorialização, desterritorialização e reterritorialização estão ligados, complementam-se incessantemente, pois são aspectos da vida diária dos sujeitos sociais e a mobilidade dos migrantes. Para este mesmo autor, estes migrantes criam territorialidades, reterritorializando e reproduzindo aspectos da forma de vida anterior, cultural, econômica e politicamente. Nesse contexto, Brum Neto (2012, p. 71) afirma:

Os constantes movimentos de desterritorialização e reterritorialização correspondem, numa ampla acepção, ao movimento da vida, ou movimento dialético, de infinita dinâmica social. Nessa relação dinâmica, em que a territorialização torna-se apenas o princípio desencadeador do processo de identificação territorial [...].

É importante entender que as territorialidades são compreendidas como relações cotidianas humanas e de produção e reprodução do espaço. Na visão de Haesbaert (2005), a territorialidade congrega as relações econômicas e culturais, estando ligada ao modo como as pessoas utilizam a terra, como elas próprias se organizam no espaço e como elas dão significado ao lugar. 
De acordo com Saquet (2015), a territorialidade é entendida a partir de quatro aspectos fundamentais: (a) como relações sociais, identidade, desigualdades, (b) apropriação, implicando dominação e delimitação espacial, (c) comportamentos, desejos, metas, sentimentos e (d) práticas espaciotemporais. Então, quando passa a ocupar espaços no Brasil, o imigrante italiano começa a se apropriar e transformar esses espaços com práticas, relações, modos de vida e aspectos da cultura e identidade desse grupo social.

A delimitação do território foi estabelecida, inicialmente a partir dos lotes que os imigrantes receberam e as possíveis migrações para as proximidades, num movimento de expansão territorial. Esta delimitação ainda é percebida no espaço pela cultura que separa os territórios da cultura italiana dos demais espaços no Rio Grande do Sul.

A partir das colocações anteriores, o território é visto também pelo seu caráter cultural (simbólico), estando ligado à questão de identidade e pertencimento de um grupo ou indivíduo. Nessa abordagem, Woodward (2000) afirma que: as identidades adquirem um sentido por meio de símbolos e sentidos, sendo expressão de um território.

Para Castells (2006), a identidade é um conjunto de características e experiências específicas de um povo, ou seja, traços que o diferem de outros grupos; estando sempre em constante processo está a constituição das identidades. $\bigcirc$ conceito de identidade pode ser pensando também como sentimento individual ou coletivo de pertencimento a algo, a alguma coisa, podendo referir-se a coisas e pessoas. Já o sentimento de pertencimento, por sua vez, implica no movimento de semelhanças ou igualdades, a busca dos iguais (Kozenieski; Medeiros, 2008).

Nesse sentido, identidade social e identidade territorial se relacionam, pois, as identidades sociais e culturais remetem a criação de territorialidades e do próprio território. Conforme Haesbaert (1999, p. 172) "toda identidade territorial é uma identidade social, definida fundamentalmente através do território, ou seja, dentro de uma relação de apropriação que se dá tanto no campo das ideias, quanto na realidade concreta".

Assim, as identidades estão presentes em todos os territórios e pertencem à natureza do sujeito, que, ao nascer, adquire uma identidade que o condiciona a determinado grupo e/ ou etnia. Nesse sentido, afirma Buchmann (1995), todos têm uma identidade expressa por valores, crenças, comportamentos e ideias que os diferenciam uns dos outros. Sendo dessa maneira, a identidade marcada pela cultura, tradição e nacionalidade, permitindo aproximação social e adaptação territorial.

Esta apropriação vista por meio da identidade é percebida no processo de colonização italiana realizado no Brasil, cujos colonos procuraram interagir com outras pessoas vindas da Itália e que apresentavam costumes e valores semelhantes, articulando o espaço em territórios culturais, marcados pela presença densa, inicialmente de italianos e, posteriormente, de descendentes italianos. São exemplos desses tipos de territórios a Serra Gaúcha e a Quarta Colônia, ambos situados no Rio Grande do Sul.

Com isso, Manfio (2012, p. 35) salienta que "a cultura italiana no território rio-grandense criou um cenário, além de inúmeras paisagens próprias às características das suas tradições, tentando reproduzir nesta terra a Itália, lugar de origem deste povo". 
Desse modo, os colonizadores italianos reafirmam características que remetem ao passado, à sua pátria de origem como o processo de reconstrução identitária, perpetuando aos seus descendentes valores e costumes que se mantêm vivos por meio da memória, contato com amigos e parentes vindos da Itália, lembranças e fotografias antigas (Briskievicz, 2012).

Ressalta Briskievicz (2012, p. 39-40) que "um descendente de italiano que vive no Brasil, sustenta relações familiares, tem lembranças de enraizamento, adquire costumes vinculados à identidade de origem, à consciência e ao sentimento".

Obviamente que ao se reterritorializarem no Brasil parte da cultura e identidade foram sendo recriadas no novo território, permanecendo a essência cultural entre os italianos, que foi passada para seus descendentes. Segundo Saquet (2007), no século XIX, muitos imigrantes italianos viveram na viagem distintas situações, ações e reações (morte). Todavia, no Brasil, reproduziram a vida por meio de experiências e conhecimentos apreendidos na antiga pátria. Houve mudanças em sua vida, mas se mantiveram uma continuidade de relações (com parentes próximos e amigos do país de origem) e um sentimento de pertencimento à terra italiana.

\section{Território e identidade da Serra Gaúcha e da Quarta Colônia (RS)}

O processo de colonização italiana no Brasil aconteceu no século XIX, devido às várias necessidades desse território, entre as quais estavam a falta de mão de obra para trabalhar nas lavouras paulistas de café (depois da abolição da escravatura), a efetivação da ocupação do espaço sulino, o fortalecimento de uma classe intermediária voltada para a constituição de um mercado interno diversificado e o desejo do governo imperial de "branquear" a população brasileira, que era majoritariamente constituída por negros e mestiços.

Para viabilizar o projeto de colonização italiana no país, o Brasil entrou em contato com o governo italiano e fez algumas propostas para facilitar a vinda dos imigrantes. A Itália durante esse período, diante do processo de unificação nacional de seu território enfrentava grandes problemas econômicos, a pobreza e a miséria preocupavam o governo e gerava um clima de instabilidade no país.

$\bigcirc$ Brasil, por sua vez, se dispôs a custear as passagens dos imigrantes, disponibilizou uma ajuda de custo (crédito) ao imigrante para possibilitar a sua instalação assim que chegasse e os lotes de terra que os italianos recebessem, teriam um longo prazo para quitarem a dívida. Diante dessas garantias oferecidas pelo Brasil a Itália permitiu que os cidadãos que tivessem interesse poderiam migrar para o Brasil (Dal Pizzol; Sousa, 2014).

De acordo com Frosi e Mioranza (2009, p. 49), "Para a fixação dos colonos italianos no Rio Grande do Sul, o governo [...] destinou duas zonas de povoamento de terras: as terras devolutas [... d do nordeste do estado e as terras localizadas nas proximidades de Santa Maria [...]". Essas duas áreas destinadas à colonização constituem hoje os vários municípios que fazem parte da Serra Gaúcha e da Quarta Colônia.

A vinda dos colonos italianos, sobretudo para o Rio Grande do Sul, marcou o espaço por meio da cultura e identidade deste povo. Para Frosi, Faggion e Dal Crono (2008, p. 144) "[...] o universo cultural aí instaurado foi essencialmente italiano e assim se preservou durante várias décadas da história regional". 
O enraizamento cultural-identitário provocou a valorização da história e cultura, potencializando um sentimentalismo de pertença dos sujeitos locais com seus costumes e tradições advindas do processo de colonização italiana no Rio Grande do Sul, mesmo sendo alguns aspectos culturais alterados a partir da vivência e das trocas culturais com outras etnias também presentes neste lugar (Froehlich et al., 2009).

Nesse contexto, os costumes e valores, passados de geração em geração, permaneceram materializados visivelmente (monumentos, igrejas, capitéis, casas, formas concretas) e invisivelmente (histórias, memórias, ensinamentos, relações, entre outras) nos territórios formados por esses migrantes. Esta identidade cria um sentimento de pertencimento nos moradores destes territórios.

Ainda, esses territórios se caracterizam por: religiosidade católica romana, paisagem dos vinhedos conduzidos na forma latada e elaboração de vinho, festividades que visam resgatar o imaginário dos primórdios da colonização, dialeto vêneto, gastronomia conhecida como típica italiana (queijo e salame, polenta, fortaia - um tipo de omelete de ovos -, risoto, massas, nhoque, tortellini), entre outras.

No que tange à gastronomia, Brum Neto (2017, p. 20) diz que "a reterritorialização acarretou algumas transformações na culinária típica, através das adaptações, principalmente em relação à disponibilidade dos ingredientes utilizados na preparação dos pratos". Assim, como houve transformações na produção do vinho, no dialeto e nas relações cotidianas.

Ademais, muitas das receitas culinárias dos imigrantes italianos não foram escritas apenas repassadas aos seus descendentes por meio da oralidade, o que acabou modificando alguns pratos típicos, em virtude do esquecimento de ingredientes, ou se tornaram peculiares a determinados lugares, nos quais as lembranças foram mais nítidas.

Nessa perspectiva, os territórios da Serra Gaúcha e da Quarta Colônia são fortemente expressivos, no entendimento da cultura e valorização desta sobre a paisagem pela manutenção dos elementos culturais pelos descendentes de italianos. São territórios que se despontaram economicamente, inicialmente pela agricultura e pela industrial artesanal. Hoje, a Serra Gaúcha exerce uma importância nacional no setor do vinho e no turismo.

\section{Serra Gaúcha: a uva, o vinho e a religiosidade católica como elementos identitários do território de colonização italiana}

Anteriormente a colonização italiana, a Serra Gaúcha recebeu imigrantes franceses e suíços, porém nem uma dessas duas etnias conseguiu se adaptar as difíceis condições impostas pela natureza e se fixar na região. Pois, o isolamento e a distância dos centros urbanos contribuíram para que a maioria dos imigrantes europeus migrasse para outros lugares do estado. De acordo com Dal Pizzol e Sousa (2014, p. 59), "[... foram alocadas 48 familias de imigrantes suíço-franceses que, diante das dificuldades, ao término das antecipações financeiras de assistência governamental, se retiraram, em quase sua totalidade, sem que houvesse sido abatida uma árvore sequer.".

Os primeiros italianos, por sua vez, começaram a chegar ao lugar em 1875 e, conforme Frosi e Mioranza (2009, p. 49-50), fixaram-se "nos fundos da Colônia Nova Palmira, onde hoje está nova Milano. No mesmo ano de 1875, criaram-se três núcleos de colonização italiana: Colônia Caxias, Colônia Dona Isabel e Colônia Conde D’Eu". Tendo em vista, que a vinda 
de italianos ocorria em grande escala para o Rio Grande do Sul, a partir da década seguinte foram demarcadas novas colônias para receberem os colonos que continuavam a chegar. Após os desmembramentos das colônias e a emancipação em diversos municípios, a Serra Gaúcha ficou configurada em 55 municípios (Figura 1), sendo denominada pela maioria dos estudiosos Região de Colonização Italiana do nordeste do Rio Grande do Sul - RCI (Frosi; Mioranza, 2009).

Para Busato e Mayer (2016), os colonos que se estabeleceram na Serra Gaúcha eram pobres, mas não eram miseráveis. Os italianos não costumavam comentar as dificuldades que enfrentaram em seu país de origem antes de partir para o Brasil.

À medida que se foram territorializando, esses colonos passaram a implantar na Serra Gaúcha os costumes e hábitos que mantinham na Itália, com o intuito de relembrar sua origem, manter sua identidade e tradição presentes na nova pátria como, por exemplo, o filó, a religiosidade católica, que passou a ter mais de uma variação na comunidade, e o trabalho ligado à vitivinicultura. Nesse lugar, conforme Busato e Mayer (2016, p. 4), "estava sendo formada e idealizada uma identidade étnica e cultural, jamais vivenciada", e as territorialidades aos poucos foram moldando e dando forma ao território.

A cultura da uva e do vinho com a chegada dos italianos e sua dedicação a este oficio "revolucionou" a vitivinicultura não somente na Serra Gaúcha, mas também proporcionou com o passar dos anos a expansão de áreas de cultivo de vinhedos para outras partes do território brasileiro, como Minas Gerais, São Paulo, Santa Catarina, Paraná. Os colonos trouxeram consigo durante a viagem transatlântica mudas de videira e o conhecimento referente à produção de vinhos, tendo em vista, que vários deles se dedicavam ao cultivo de vinhas em seu país de origem antes de se mudar para o Brasil.

\section{Figura 1 - Localização da Serra Gaúcha}
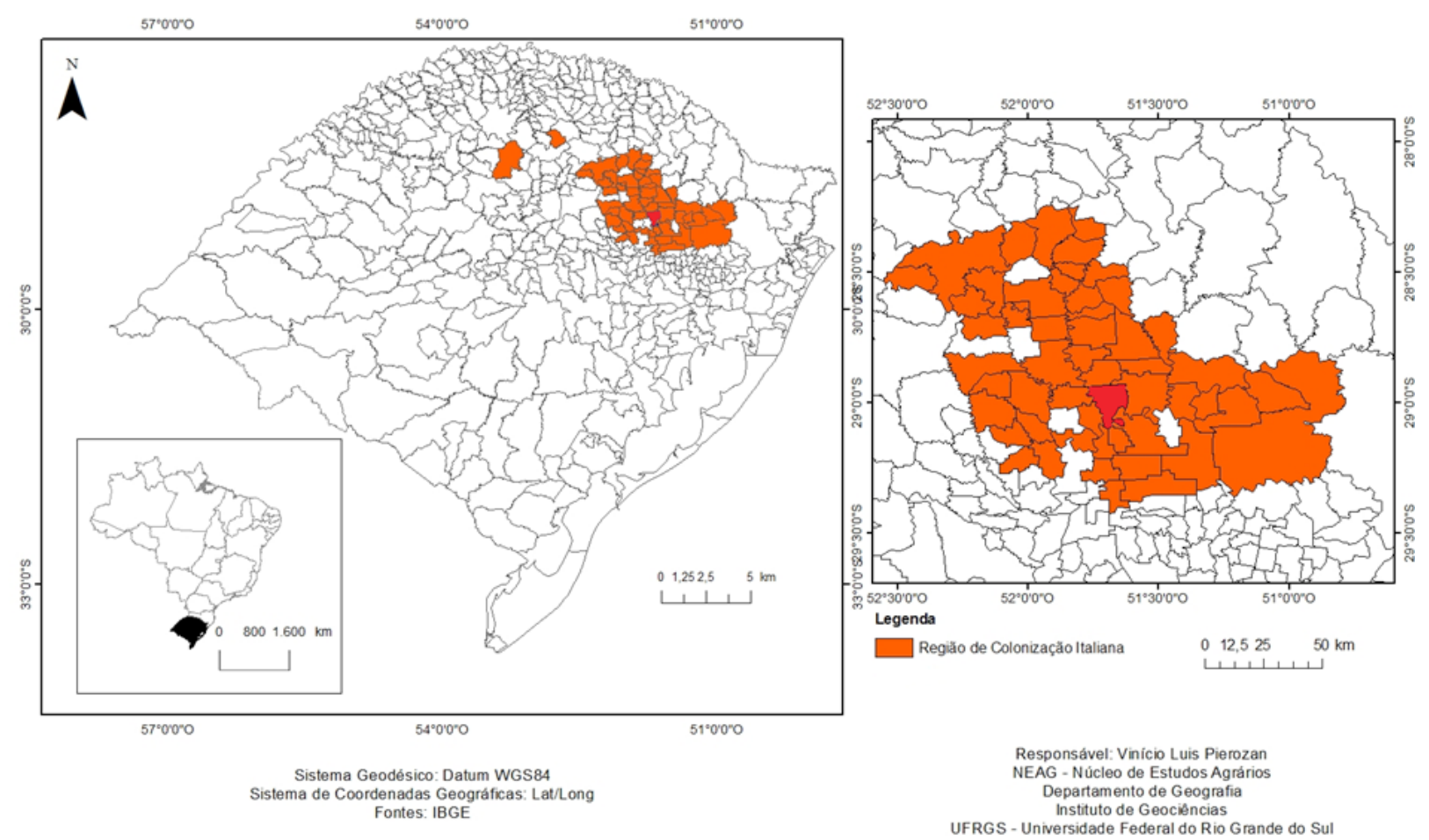

fonte: Pierozan (2018). 
Na Serra Gaúcha, a uva e o vinho são produzidos em pequenas propriedades rurais, nas quais trabalham nos parreirais apenas os membros da familia. Às vezes, existe contrato de funcionários apenas no período de poda e vindima, quando a demanda por trabalho nos vinhedos aumenta consideravelmente (Pierozan; Manfio; Medeiros, 2017, p. 4719).

Somando-se ao trabalho realizado com a vitivinicultura, na região também são realizadas diferentes festividades que têm a uva, o vinho e o colono italiano como elementos característicos e típicos do lugar. Entre as principais destaca-se A Festa Nacional da Uva, que ocorre em Caxias do Sul e busca resgatar e valorizar a presença do italiano na região. De acordo com Valduga (2011, p. 128), "o evento tornou-se patrimônio da comunidade, [...] houve a identificação do grupo ao território, ancorando um passado ao trabalho e projetando um futuro com base nos mesmos princípios e ideais, fundado numa memória comum".

Com o passar dos anos, além de mostrar a cultura e a Serra Gaúcha para todo o país, a festividade passou a receber também milhares de turistas, inclusive estrangeiros, que, além de participar da festa, buscam conhecer os demais municípios vizinhos produtores de uva e vinho. O turismo, por sua vez, ganhou um calendário anual e tem atividades culturais, artísticas, gastronômicas e de lazer voltadas para os mais diferentes públicos em todos os meses do ano. A paisagem exuberante do lugar, repleta de encostas recobertas por vinhedos (Figura 2), é outro importante atrativo procurado e apreciado por visitantes que desejam conhecer a região.

\section{Figura 2 - Vinhedo em Bento Gonçalves}

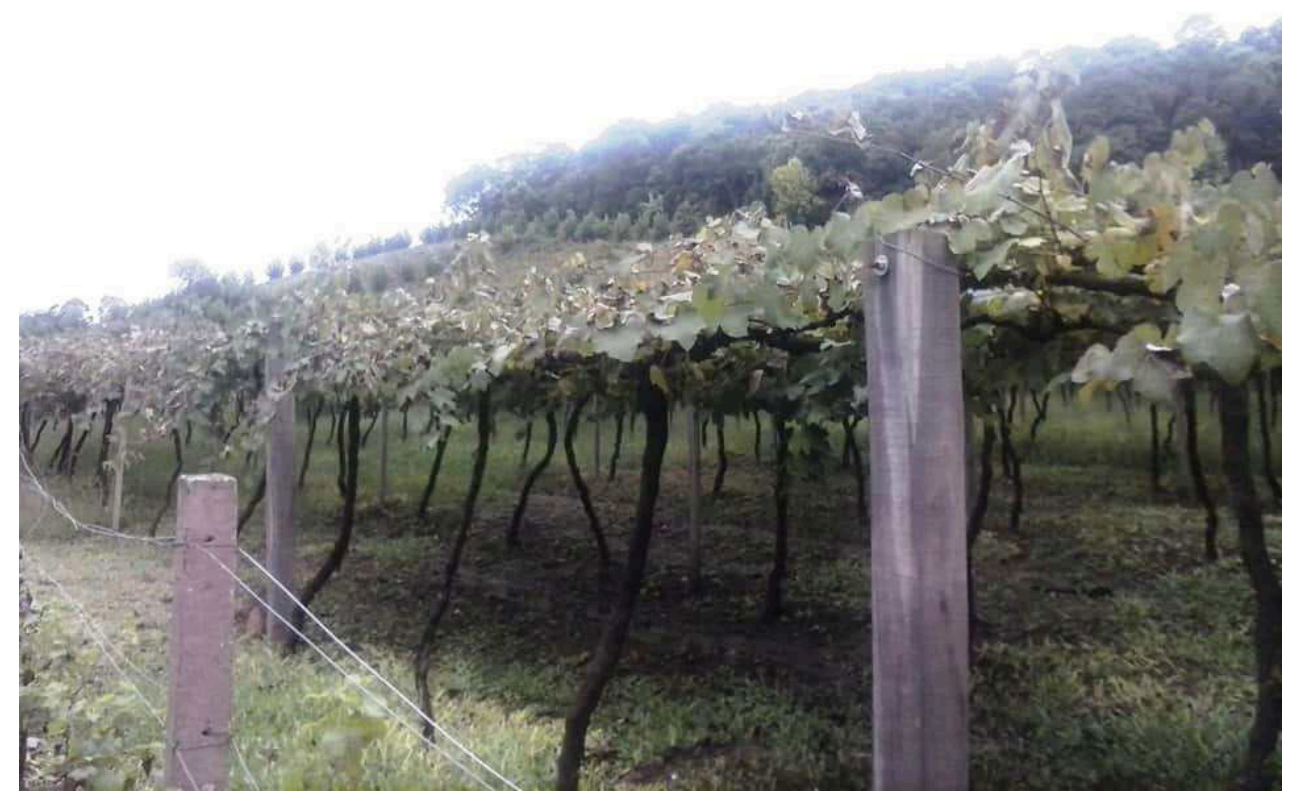

fonte: Manfio (2017).

Entidades ligadas ao turismo como hotéis e empresas de turismo com vistas, a atender essa demanda juntamente com as vinícolas procuraram criar e ofertar aos visitantes diferentes oportunidades para aproximar o turista dos vinhedos. Nesse sentido foram criadas diversas 
rotas enoturísticas, como, por exemplo, a Rota dos Espumantes (Garibaldi), a Rota das Cantinas Históricas (Bento Gonçalves), os Caminhos do Moscatel (Farroupilha) e o Roteiro dos Vinhos dos Altos Montes (Flores da Cunha), que contam com passeios e percursos voltados para a visita dos vinhedos, vinícolas familiares e grandes vinícolas situadas nos diferentes municípios da região. Destacam-se, por exemplo, os passeios de tuque-tuque (caminhão que transporta uva) entre os parreirais, o merendim (lanche típico realizado pelos colonos italianos entre as vinhas em que são degustados queijo, salame, copa, vinho, suco de uva, biscoitos e pães artesanais), a colheita e pisa da uva e para os mais aventureiros passeios ciclísticos, como o Passeio Ciclístico de Primavera, que tem seu percurso realizado entre os diversos vinhedos cultivados no município de Bento Gonçalves.

A religiosidade católica também sempre esteve presente na Serra Gaúcha desde a chegada dos primeiros colonos que assim que se estabeleciam iam construindo igrejas e capitéis dedicados aos seus santos padroeiros. Um dos diversos expoentes da religiosidade dos colonos italianos que iam buscando se fixar no território é o Campanário de São Vicente (Figura 3), construído em 1905 no município de Cotiporã, lugar onde foi realizada a primeira missa na antiga Colônia de Monte Vêneto, que mais tarde deu origem ao município.

\section{Figura 3 - Campanário da Capela São Vicente, Cotiporã}

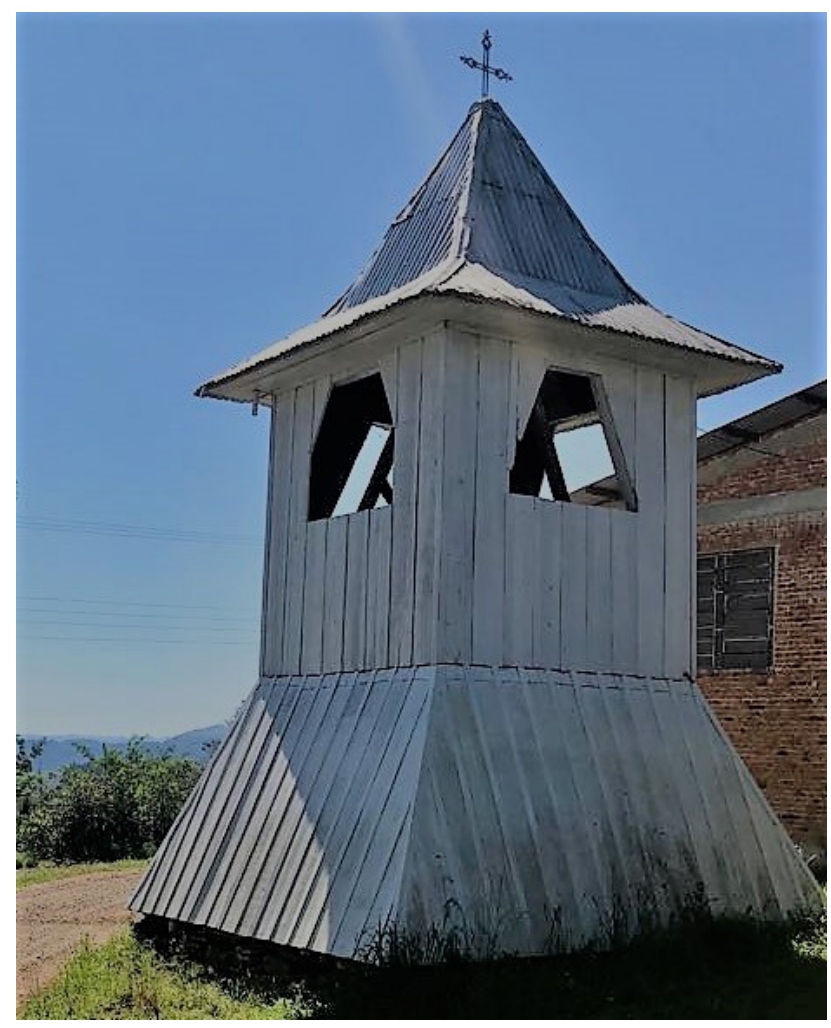

fonte: Pierozan (2018).

$\bigcirc$ vinho também esteve lado a lado com a fé dos italianos num dos momentos de maior necessidade ocorrido durante um período de seca prolongado, que se estendeu por aproximadamente dois anos no início do século XX. A continuidade da construção da Capela da Nossa Senhora das Neves (Figura 4), situada no Vale dos Vinhedos, município de Bento Gonçalves, 
em virtude da seca para não ter a obra paralisada pela falta da água recebeu vinho na constituição da argamassa, que foi utilizada na sustentação a igreja. $\bigcirc$ vinho usado proveio de familias locais, que doaram parte da produção vinícola de safras de anos anteriores estocadas nos porões das casas dos colonos (Aprovale, [2018?]).

\section{Figura 4 - Igreja Nossa Senhora das Neves}

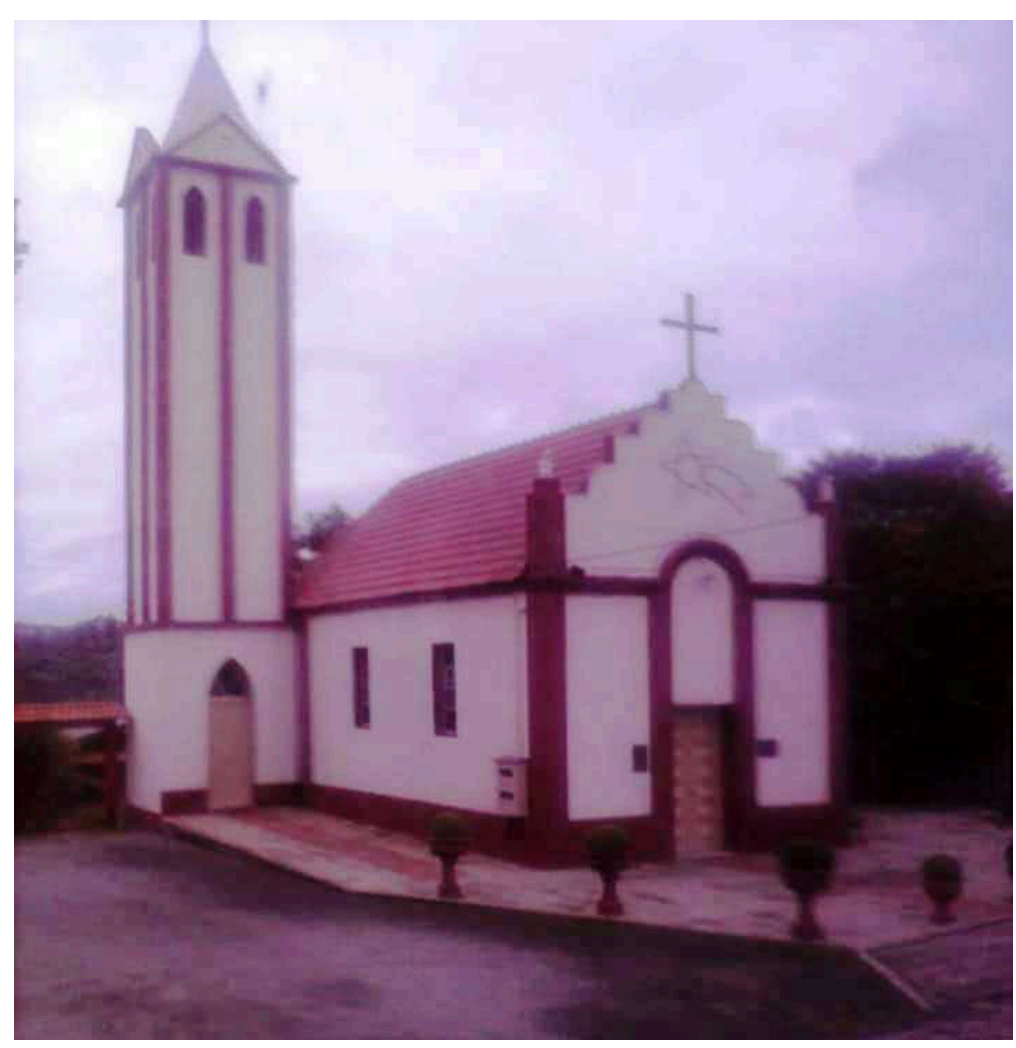

fonte: Manfio (2017).

As festas dedicadas ao santo da comunidade (capela), ou patrono do município continuam sendo realizadas anualmente, juntamente com romarias, novenas e peregrinações, uma das mais tradicionais é a dedicada ao Santuário de Nossa Senhora de Caravaggio, situado no município de Farroupilha. Anualmente milhares de peregrinos se deslocam ao santuário para agradecer ou buscar a interseção da santa para a realização de uma graça, é comum os fiéis percorrerem diversos quilômetros a pé como forma de agradecimento a interseção da santa e/ou devoção.

O Corpus Christi, celebrado depois de transcorridos sessenta dias da Páscoa, é uma tradição da igreja católica que teve início no século XIII e que é muito celebrada nos municípios da RCl. A data é marcada por procissões e pelos tapetes coloridos confeccionados com serragem colorida.

Os tapetes cobrem as principais ruas e vias públicas por onde a procissão é realizada, costumam ser feitos vários dias antes da celebração por estudantes e voluntários. A gastronomia juntamente com a vitivinicultura e a religiosidade, marcam a cultura italiana na Serra Gaúcha. São territorialidades presentes do território da cultura italiana envolvendo uma sociedade e o seu espaço, bem como as relações de poder, aspirações e oportunidades presentes no ato de tecer este território. 
Quarta Colônia (RS): aspectos da identidade, da cultura e do território

A Colônia de Silveira Martins (Quarta Colônia) se constituiu num dos núcleos coloniais ocupados pelos italianos no Rio Grande do Sul e está situada na região central do estado. Os primeiros colonos chegaram à região por volta de 1877.

Segundo Saquet (2003, p. 83), "Na Colônia Silveira Martins, as primeiras turmas foram alojadas num barracão, na base da encosta do planalto. Esse lugar foi denominado Val de Buia devido à presença de italianos provenientes de Buia, província de Údine, Itália". A contínua chegada de imigrantes fez surgirem vários núcleos dentro da colônia Silveira Martins: núcleo Norte, núcleo Soturno, núcleo Treviso, Silveira Martins, Vale Vêneto, Arroio Grande (Saquet, 2003).

Convém destacar que o desmembramento da Colônia Silveira Martins resultou na formação da Quarta Colônia de Colonização Italiana (Figura 5), dos quais fazem parte os municípios de: Dona Francisca, Faxinal do Soturno, São João do Polêsine, Ivorá, Silveira Martins, Nova Palma e Pinhal Grande.

Figura 5 - Localização dos municípios pertencentes à Quarta Colônia

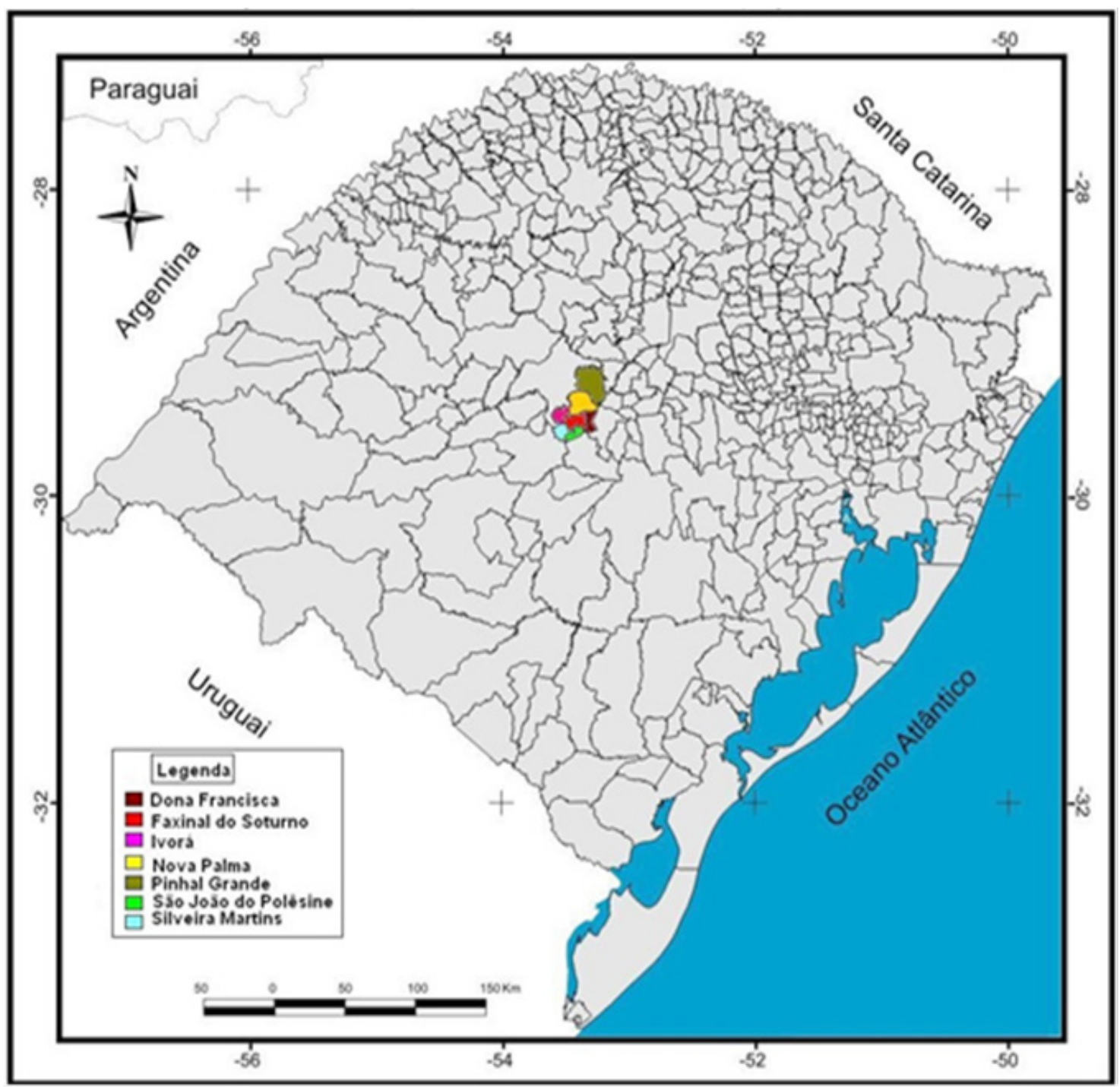

fonte: Manfio (2018). 
Retomando, os imigrantes italianos foram responsáveis pela apropriação do espaço a partir de sua vivência, seus costumes, suas relações e suas construções. Assim, construíram casas de pedras ou madeiras, com características semelhantes à arquitetura italiana, com telhados inclinados, porões grandes (para armazenamento de produtos e alimentos), cozinhas - geralmente separadas dos outros cômodos da residência, devido a sua funcionalidade de reunião familiar -, casas com várias janelas e quartos, pois constituíam famílias grandes e numerosas (Manfio; Benaduce, 2017).

Muitas casas como, por exemplo, a Casa Alberto Pasqualini de Ivorá, o casarão dos Manfios (Figura 6) e a residência da Família Rossato em Nova Palma, pertenceram aos primeiros colonos italianos que se estabeleceram ali. Essas casas foram ampliadas e reformadas e ainda estão preservadas no território, sendo, nos dias de hoje, habitada por seus descendentes, fato que permite valorizar toda a trajetória histórica da família e cria no morador um forte sentimento de pertencimento a aquele lugar. Outras, porém não servem mais de moradia, devido a sua deterioração, mas são cultuadas como patrimônio cultural.

\section{Figura 6 - Casarão dos Manfios}

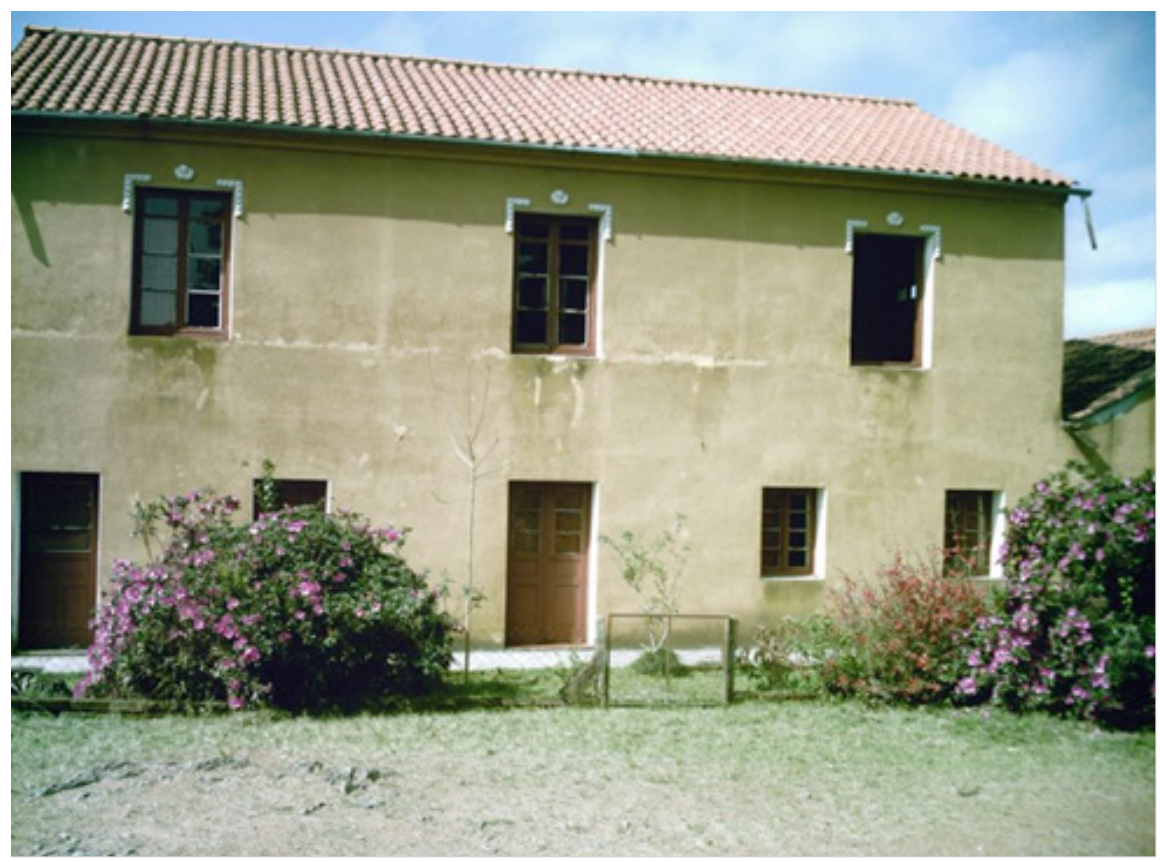

fonte: Manfio (2011).

A construção destas casas era feita com materiais próprios e disponíveis aos imigrantes, geralmente os tijolos, que eram construídos em olarias destas propriedades e ou pedras e ferros disponíveis aos imigrantes, fazendo com que suas técnicas de construção foram importantes e reconhecidas (Venturini; Gaspary, 2015).

Não apenas na arquitetura os imigrantes deixaram seu legado nos territórios que constituíram, mas também na construção de símbolos religiosos e na fé. Os italianos que chegaram da Colônia Silveira Martins edificaram igrejas e capitéis no seu território, demonstrando a forte religiosidade católica deste povo. A fé sempre acompanhou os momentos difíceis enfrentados por este povo ao longo da colonização e servia como estímulo para superar as adversidades 
encontradas no cotidiano. Manfroi (2001, p. 120) destaca que os italianos "abandonados e perdidos no meio da floresta virgem, eles se reencontravam consigo mesmo e com os outros, através da prática da religião, ritmos e cerimônias".

Após a colonização, os descendentes de italianos mantiveram a religiosidade. Esta é percebida na Quarta Colônia pela grande presença de santos padroeiros, quadros, altares e capelas construídas nas casas destes descendentes, para a pregação do terço diariamente pela família (Manfio; Benaduce, 2017). Algumas casas tinham anjos desenhados nas bordas de fora das janelas e portas, representando um apelo à proteção espiritual.

A igreja servia para esse povo, principalmente nos primeiros anos de colonização, como um ponto de encontro para rever amigos, familiares e demais conhecidos da comunidade que moravam mais afastados, mas que aos domingos se deslocavam para a igreja para assistir à missa. Após as celebrações dominicais os homens jogavam baralho e as mulheres conversavam, este espaço de convívio social ocorria junto ao Salão Paroquial, que se situava nas proximidades da igreja. Segundo Saquet (2003, p. 93), "após a missa, aproveitavam para fazer compras e jogar bocha e baralho (Tressette) sempre acompanhados do vinho".

Assim, a religiosidade católica é outro aspecto fundamental da identidade cultural da região, pois estão materializados os elementos deste universo como: capelas, monumentos aos religiosos já falecidos, grutas, capitéis, altares religiosos nas casas, igrejas (Figura 7).

\section{Figura 7 - Igreja Santíssima Trindade de Nova Palma (RS)}

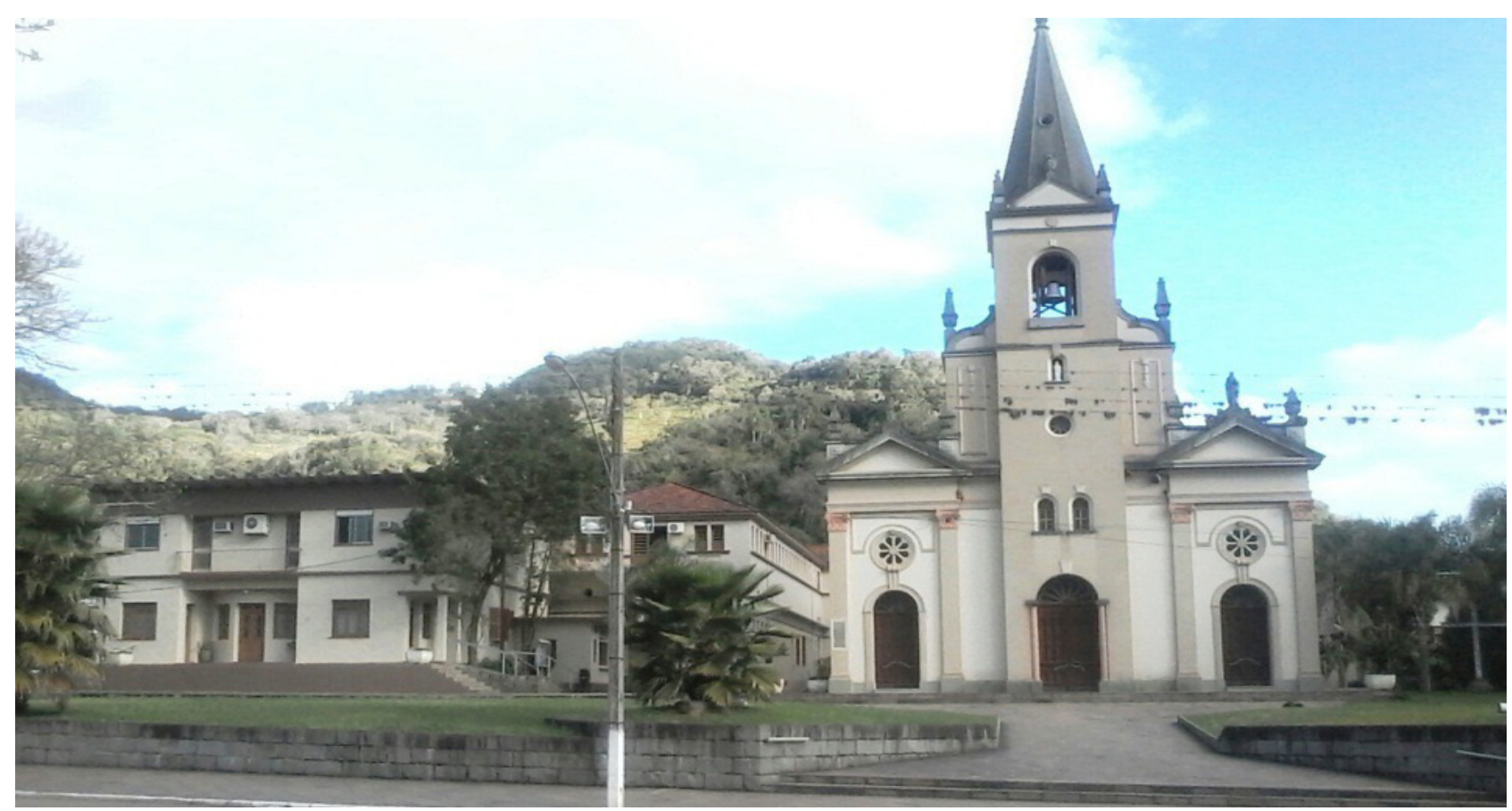

fonte: Manfio (2016).

Na Quarta Colônia, atualmente existe a tradição de circular entre as famílias capelinhas de Nossa Senhora. As capelinhas são distribuídas em quadras urbanas ou comunidades rurais, nas quais cada família deve ficar um dia com a Nossa Senhora e passar para residência vizinha, fazendo a capelinha o percurso de visitas aos moradores durante um mês. Em Nova Palma 
existem três capelinhas diferentes que circulam nas casas da cidade, Nossa Senhora de Schoenstatt, Nossa Senhora de Fátima, Nossa Senhora Medianeira, ambas tem vários exemplares. Assim, as famílias rezam e recebem a visita da capelinha. É, contudo, uma maneira de preservar a religiosidade, mas também a noção de comunidade, pelo fato dela ser compartilhada com os moradores de um espaço.

Além da religiosidade, o trabalho seguiu técnicas e ensinamentos trazidos da velha pátria (Itália), voltado à produção diversificada de produtos agrícolas; assim como as técnicas de manufaturas e comércio também foram sendo desenvolvidas no urbano-rural da Colônia Silveira Martins (Saquet, 2003). Os imigrantes da Quarta Colônia e seus primeiros descendentes no Brasil construíram moinhos que operavam com roda d'água, olarias, serrarias, alambiques e cantinas (Venturini; Gaspary, 2015). No trabalho eram utilizadas ferramentas trazidas da Itália ou criadas na própria colônia como: enxadas, foices, machadinhos, arados, entre outras (Saquet, 2003).

Portanto, o trabalho e a religiosidade desencadearam territorialidades específicas no território formado pelos imigrantes italianos e seus descendentes, vistas a partir do modo de vida e das práticas diárias. Nessas práticas diárias, a culinária representa um papel importante, pois é alimento e também cultura.

Essas comidas, ainda são frequentemente servidas em festivais e em espaços coloniais da região. Entre as festas estão os cafés coloniais, Festa da Uva (Silveira Martins), Festa do Vinho e Queijo (Faxinal do Soturno), festas de santos padroeiros, entre outras.

$\bigcirc$ vinho é um elemento bastante significativo na paisagem da Quarta Colônia, seja no rural ou urbano, é comum a presença de parreirais nos quintais das residências e nas propriedades rurais. Além disso, a elaboração da bebida é realizada artesanalmente utilizando-se de técnicas e conhecimentos aprendidos com os antepassados, que foram preservados e guardados com o passar dos anos. Claro que a vitivinicultura não atingiu marcas paisagísticas e econômicas como aconteceu na Serra Gaúcha.

A identidade italiana na Quarta Colônia também está presente nos descendentes de colonos por meio de histórias, ensinamentos e valores, que adquiriram e se constituíram num sentimento de pertencimento a esta cultura. Para Manfio e Benaduce (2017, p. 271): "a identidade e o sentimento de pertencimento são o ponto-chave da manutenção da cultura italiana na região. E por meio disso, se preserva as tradições, buscando valorizar os ensinamentos e cultivando os símbolos da cultura como patrimônio histórico - culturais.".

Este enraizamento cultural é bastante expressivo na região e possibilitou a criação de museus e centros de pesquisas para valorizar as histórias, documentos e objetos dos antepassados como, por exemplo: Museu Histórico de Vale Vêneto (São João do Polêsine), Museu Histórico de Silveira Martins, Museu Histórico Geringonza Novo Treviso (Faxinal do Soturno) e Centro de Pesquisas Genealógicas (CPG) em Nova Palma.

Destaca-se, além disso, a criação de um grupo teatral (conhecido como Frotole Del Baracon), em 1991, por descendentes de colonos italianos do município de Nova Palma, que difundiu a cultura italiana, por meio da representação da vida dos primeiros colonos, com trajes típicos dos antepassados e utilizando em suas apresentações o dialeto vêneto. Por ora, esse grupo teatral não faz mais apresentações, pois seus membros tinham outros empregos e tiveram dificuldade para manter os ensaios e as apresentações, que aconteciam semanalmente (Figura 8). 


\section{Figura 8 - Reportagem sobre o grupo teatral Frotole del Baracon}

\section{5 anos de palco e sotaque}

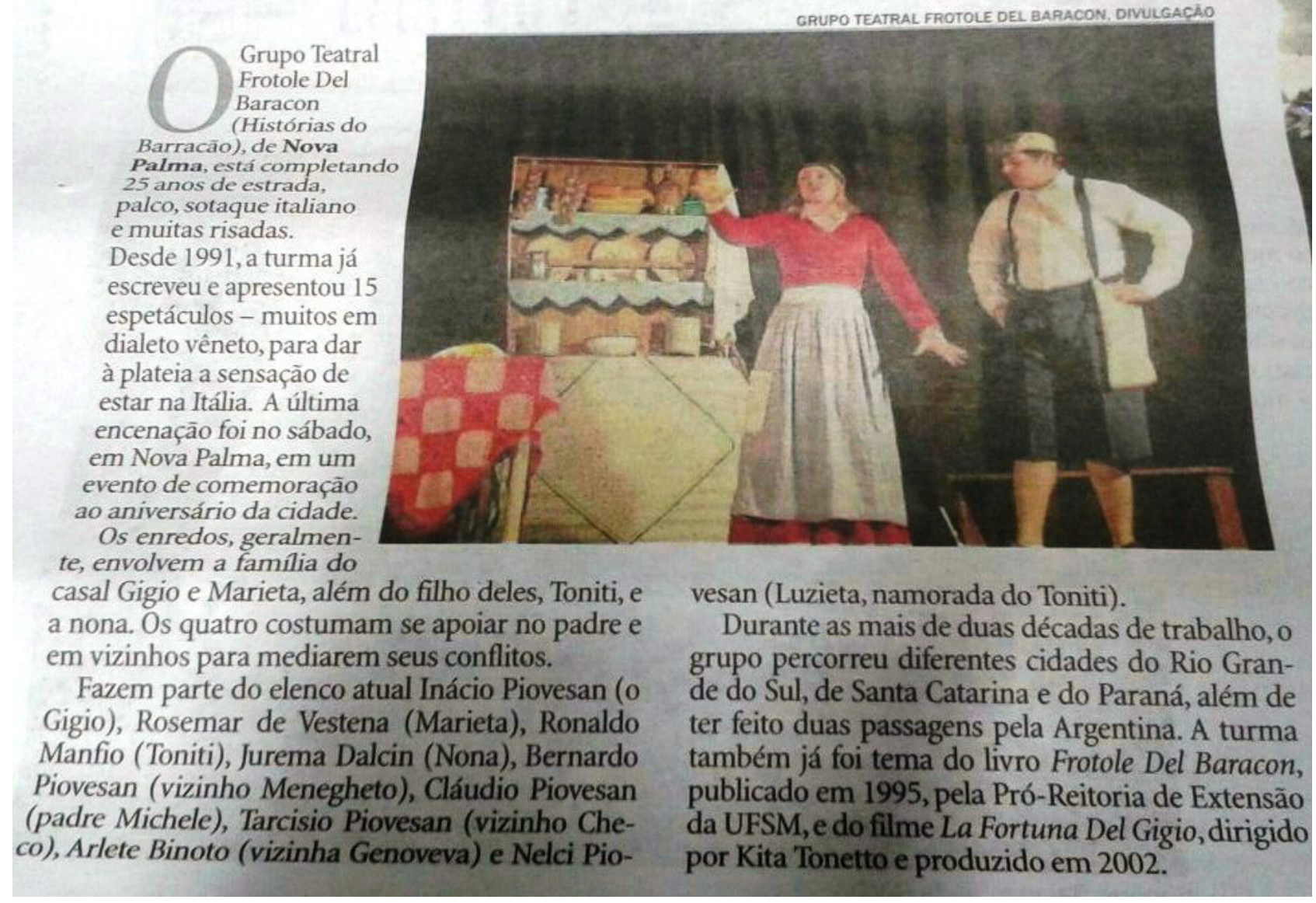

fonte: 25 anos [...] (2016).

Soma-se a essa transmissão de valores italianos a construção de monumentos em referência à colonização italiana e a comemoração do centenário da imigração italiana na Quarta Colônia, demonstram um culto a identidade cultural. Por exemplo, o Monumento do Imigrante, que foi inaugurado no dia 29 de outubro de 1977, ano do centenário da imigração italiana em Silveira Martins, mais especificamente na localidade de Val de Buia, onde se instalaram, no passado, os primeiros imigrantes italianos e seus descendentes na Quarta Colônia. Em Faxinal do Soturno, na praça municipal, também tem um monumento à imigração italiana. Ele é em forma de barco, que representa a chegada dos imigrantes italianos.

Estes vários elementos materializados e (i) materializados na Quarta Colônia representam hoje objetos de turismo. Existem algumas rotas turísticas que vem sendo criadas para promover esta riqueza de símbolos como: $\bigcirc$ Caminho da Uva e das Águas que integra as comunidades de Val de Buia e Val Feltrina em Silveira Martins, onde é possível conhecer as propriedades rurais, vinhedos, cascatas e balneários e adquirir produtos coloniais como vinho, massas (Rio Grande do Sul, [2018?]). Além deste existe a Rota Gastronômica da Imigração Italiana que integra os distritos de Arroio Grande, Vale Vêneto, Recanto do Maestro e as localidades de Val de Buia, Val Feltrina e Silveira Martins. 
É importante ressaltar que há necessidade de mais investimentos na preservação dos patrimônios culturais e no turismo para região da Quarta Colônia, a fim de não se perder as territorialidades e a cultura italiana.

Assim, verifica-se na Quarta Colônia a presença de várias territorialidades, memórias e artefatos históricos que reforçam a identidade italiana do lugar, formando um território cultural de caráter italiano em que a marca dessa cultura permeia o espaço, a sociedade e a identidade.

\section{Considerações finais}

Os territórios constituídos pelos colonos italianos na Serra Gaúcha e na Quarta Colônia, embora estejam situados em áreas territoriais distintas dentro do estado do Rio Grande do Sul, são repletos de territorialidades semelhantes. Os extensos parreirais cobrindo as áreas rurais, o costume de ter sempre em mãos um copo de vinho durante as refeições, a tradição de ir à missa aos domingos e a crença na benção divina fazem parte da grande marca dos moradores desses dois lugares e a constituem.

Mesmo com os grandes avanços verificados nos últimos anos, principalmente com as novas formas de se comunicar, advindos, em parte, da chegada da internet, o dialeto vêneto continua resistindo e marcando o espaço das conversas nos encontros depois das missas, nas idas ao mercado e à agropecuária e entre os próprios viticultores em meio aos parreirais.

As construções centenárias de identidade italiana continuam sendo restauradas ou valorizadas nos territórios dessa cultura como um mecanismo de salvaguardar a identidade e a história, assim como surgem monumentos para mostrar toda essa herança cultural, os quais marcam a vida e os lugares também pelo sentimento e pela memória dos descendentes de italianos, que têm um grande orgulho de suas raízes. Todas essas territorialidades e marcas culturais estão materializadas na paisagem e nas festividades.

Nas festas, acontece a união de música, gastronomia, danças, teatro, entre outros elementos que atraem turistas. Por fim, as territorialidades exprimem a presença da etnia italiana no lugar, reafirmam costumes e mantêm preservadas as tradições, que, há mais de um século, tanto na Serra Gaúcha quanto na Quarta Colônia, continuam a caracterizar os moradores e os dois territórios.

\section{Referências}

25 ANOS de palco e sotaque. Diário de Santa Maria, Santa Maria, 1 ago. 2016.

APROVALE. ASSOCIAÇÃO DOS PRODUTORES DE VINHOS FINOS DO VALE DOS VINHEDOS. História. Bento Gonçalves, [2018?]. Disponível em: http://www. valedosvinhedos.com.br/vale/conteudo.php?view=73 Eidpai=126. Acesso em: 17 set. 2018.

BRISKIEVICZ, M. Territorialidade e identidade: a migração dos descendentes de italianos no município de Francisco Beltrão, Paraná. Dissertação (Mestrado em Geografia) - Universidade Estadual do Oeste do Paraná, Francisco Beltrão, 2012. 
BRUM NETO, H. Os territórios da imigração italiana no Rio Grande do Sul-Brasil. In: SEMINÁRIO INTERNACIONAL SOBRE DESENVOLVIMENTO REGIONAL, 8., 2017, Santa Cruz do Sul. Anais... Santa Cruz do Sul: Unisc, 2017.

BRUM NETO, H. Os territórios da imigração alemã e italiana do Rio Grande

do Sul. Tese (Doutorado em Geografia) - Universidade Estadual Paulista, Presidente Prudente, 2012.

BRUM NETO, H. Regiões culturais: a construção de identidades culturais no Rio Grande do Sul e sua manifestação na paisagem gaúcha. Dissertação (Mestrado em Geografia) - Universidade Federal de Santa Maria, Santa Maria, 2007.

BUCHMANN, E. T. A trajetória do sol. Curitiba: Fundação Cultural, 1995.

BUSATO, M. C. M.; MAYER, L. Identidade e pertencimento: um olhar sobre a colonização italiana e alemã no Sul do Brasil durante os séculos XIX e XX. Boletim Historiar, São Cristóvão, n. 13, p. 50-66, jan./fev. 2016.

CASTELLS, M. O poder da identidade. Rio de Janeiro: Paz e Terra, 2006.

DAL PIZZOL, R.; SOUSA, S. I. Memórias do vinho gaúcho. Porto Alegre: AGE, 2014.

FELIN, S. Quarta colônia: identidade, fundação, costumes e tradições de Vale Veneto. Revista Latino-Americana de História, São Leopoldo, RS, v. 2, n. 6, p. 356- 367, ago. 2013.

FIGUEIREDO, L. C. Quarta Colônia de Imigração Italiana na região central do Rio Grande do Sul: os sítios históricos na construção do patrimônio e da paisagem cultural. RA'EGA, Curitiba, v. 31, p. 147-183, ago. 2014.

FROEHLICH, J. M.; VENDRUSCOLO, R.; MACIEL, C. A. R.; DULLIUS, P. R. Narrando territorialidade: identidade territorial da Quarta Colônia-RS. In: CONGRESSO DA SOCIEDADE BRASILEIRA DE ECONOMIA, ADMINISTRAÇÃO E SOCIOLOGIA RURAL, 47., 2009, Porto Alegre. Anais... Porto Alegre, 2009. p. 1-18. Disponível em: www.sober.org.br/palestra/13/818.pdf. Acesso em: 16 nov. 2017.

FROSI, V. M.; FAGGION, C. M.; DAL CORNO, G. O. M. Prestígio e estigmatização: dialeto italiano e língua portuguesa da região de colonização italiana do nordeste do Rio Grande do Sul. Revista da Abralin, Curitiba, v. 7, n. 2, p. 137-162, jul./dez. 2008.

FROSI, V. M.; MIORANZA, C. Imigração italiana no nordeste do Rio Grande do

Sul: processos de formação e evolução de uma comunidade ítalo-brasileira. 2. ed. Caxias do Sul, RS: Educs, 2009[1975].

HAESBAERT, R. Da desterritorialização à multiterritorialidade. X Encontro de Geógrafos da América Latina, 10., São Paulo. Anais... São Paulo: USP, 2005.

HAESBAERT, R. O mito da desterritorialização: do "fim dos territórios" à multiterritorialidade. Rio de Janeiro: Bertrand Brasil, 2004.

HAESBAERT, R. Identidades territoriais. In: CORRÊA, R. L.; ROSENDAHL, Z. (Org.). Manifestações da cultura no espaço. Rio de Janeiro: Ed. Uerj, 1999. p 169-190. 
KOZENIESKI, E. M.; MEDEIROS, R. M. V. O processo de reterritorialização dos moradores no condomínio Campos Cristal em Porto Alegre-RS. In: ENCONTRO NACIONAL DE GRUPOS DE PESQUISA, 4., 2008, São Paulo. Anais... São Paulo, 2008. p. 759-781.

MANFIO, V. A Quarta Colônia de Imigração Italiana: uma paisagem cultural na região central do Rio Grande do Sul. Geografia Ensino E Pesquisa, Santa Maria, RS, v. 16, n. 2, p. 31-46, maio/ago. 2012.

MANFIO, V. O papel da Camnpal na (re)estruturação do espaço urbano de Nova Palma-RS. Dissertação (Mestrado em Geografia) - Universidade Federal de Santa Maria, Santa Maria, 2011.

MANFIO, V.; BENADUCE, G. M. C. Quarta Colônia de Imigração Italiana-RS: uma abordagem sobre a cultura e identidade. Geosul, Florianópolis, v. 32, n. 65, p. 260-273, set./dez. 2017.

MANFIO, V.; BENADUCE, G. M. C. A Quarta Colônia de Imigração Italiana: a valorização cultural da região. In: SIMPÓSIO DE ENSINO, PESQUISA E EXTENSÃO, 14., 2010, Santa Maria. Anais... Santa Maria, 2010. Disponível em: http://www.unifra.br/eventos/sepe2010/2010/Trabalhos/humanas/Completo/4596.pdf. Acesso em: 12 fev. 2018.

MANFROI, O. A colonização italiana no Rio Grande do Sul: implicações econômicas, político e culturais. 2. ed. Porto Alegre: EST, 2001.

MEDEIROS, R. M. V. Território, espaço de identidade. In: SAQUET, M. A.; SPOSITO, E. S. (Org.). Território e territorialidades: teoria, processos e conflitos. São Paulo: expressão Popular, 2009. p. 217-228.

PICCIN, E. O código cultural religião como uma das manifestações da identidade cultural da Quarta Colônia de Imigração Italiana-RS. Dissertação (Mestrado em Geografia) - Universidade Federal de Santa Maria, Santa Maria, 2009.

PIEROZAN, V. L.; MANFIO, V.; MEDEIROS, R. M. V. O vinho, a cultura e o espaço: a constituição de paisagens geográficas no Vale dos Vinhedos e Campanha Gaúcha-RS. In: ENCONTRO NACIONAL DA ASSOCIAÇÃO NACIONAL DE PÓS-GRADUAÇÃO EM GEOGRAFIA, 12., 2017, Porto Alegre. Anais... Porto Alegre, 2017. p. 4714-4725. Disponível em: http://www.enanpege.ggf.br/2017/anais/. Acesso em: 2 maio 2018.

REIS, S. S. Quarta Colônia: aspectos de sua identidade cultural/territorial. Boletim Gaúcho de Geografia, Porto Alegre, n. 23, p. 97-104, mar. 1998.

RIO GRANDE DO SUL. Secretaria da Cultura, Turismo, Esporte e Lazer. Turismo e Silveira Martins. Porto Alegre, [2018?]. Disponível em: www.turismo.rs.gov.br/cidade/386/silveiramartins. Acesso em: 20 ago. 2018.

SANTI, S. Sonhos diferenciados ou desfeitos: Silveira Martins, a Quarta Colônia, no cenário da imigração italiana no Rio Grande do Sul. In: MARIN, J. (Org.). Quarta Colônia: novos olhares. Porto Alegre: EST, 1999. p. 11-21. 
SAQUET, M. A. Por uma geografia das territorialidades e das temporalidades: uma concepção multidimensional voltada para cooperação e para o desenvolvimento territorial. Rio de Janeiro: Consequência, 2015.

SAQUE T, M. A. As diferentes abordagens do território e a apreensão do movimento e da (i) materialidade. Geosul, Florianópolis, v. 22, n. 43, p. 55-76, jan./jun. 2007.

SAQUET, M. A. Os tempos e os territórios da colonização italiana. Porto Alegre: EST, 2003.

SAQUET, M. A. Alguns aspectos da formação econômica da ex-colônia Silveira Martins (1878-1925). In: MARIN, J. (Org.). Quarta Colônia: novos olhares. Porto Alegre: EST, 1999. p. 56-73.

SAQUET, M. A.; BRISKIEVICZ, M. Territorialidade e identidade: um patrimônio no desenvolvimento territorial. Caderno Prudentino de Geografia, v. 1, n. 31, p. 3-16, 2009.

SPONCHIADO, B. A. Imigração \& Quarta Colônia: Nova Palma e Pe. Luizinho. Nova Palma, RS: Paróquia Santíssima Trindade/Ed. UFSM, 1996.

VALDUGA, V. Raízes do turismo no território do vinho: Bento Gonçalves e Garibaldi - 1870 a 1960 (RS-Brasil). Tese (Doutorado em Geografia) - Instituto de Geociências, Universidade Federal do Rio Grande do Sul, Porto Alegre, 2011.

VENTURINI, A P. M.; GASPARY, F. P. O legado arquitetônico da imigração italiana no Rio Grande do Sul: o moinho Moro. Disciplinarum Scientia, Santa Maria, v. 16, n. 1, p. 11-19, 2015.

WOODWARD, K. Identidade e diferença: uma introdução teórica e conceitual. In: SILVA, T; HALL, S.; WOODWARD, K. (Org.). Identidade e diferença: a perspectiva dos estudos culturais. Petrópolis, RJ: Vozes, 2000. p. 7-72.

ZANINI, M. C. C. Pertencimento étnico e territorialidade: italianos na região central do Rio Grande do Sul (Brasil). Redes, Santa Cruz do Sul, v. 13, n. 3, p. 140-163, set./dez. 2008

ZANINI, M. C. C. Entre memórias e identidades (étnicas). Revista História Unisinos, São Leopoldo, v. 11, n. 1, p. 40-48, jan./abr. 2007. 